Results: The study included 4886 SLE patients and 24430 age- and sex-matched controls. The SLE group had a significantly higher proportion of FMF patients compared to non-SLE controls $(0.68 \%$ and $0.21 \%$ respectively; $p<0.001)$. Table 1. All study population

Table 1. SLE patients and matched controls basic characteristics

\begin{tabular}{lccc}
\hline & No SLE & SLE & p.overall \\
\hline & $N=24430$ & $N=4886$ & \\
\hline Age & $51.2 \pm 16.5$ & $51.2 \pm 16.5$ & 1.000 \\
Gender: Female & $20100(82.3 \%)$ & $4020(82.3 \%)$ & 1.000 \\
FMF & $52(0.21 \%)$ & $33(0.68 \%)$ & $<0.001$ \\
\hline
\end{tabular}

Table 2. Stratification

Table 2. comparison of FMF patients with and without SLE

\begin{tabular}{lccc}
\hline & FMF without SLE & FMF with SLE & p.overall \\
\hline N=52 & $N=33$ & \\
\hline Age & $44.6 \pm 13.7$ & $50.5 \pm 17.7$ & 0.106 \\
Gender: Female & $45(86.5 \%)$ & $26(78.8 \%)$ & 0.523 \\
\hline
\end{tabular}

Conclusion: FMF was found to be more common amongst SLE patients compared to matched controls. The current study results suggest that the occurrence of SLE turn patients with an appropriate genetic and environmental setting to develop also FMF. This cross-sectional study sheds light on the coexistence of these two diseases, autoimmune and autoinflammatory.

References:

[1] Kucuk A, Gezer IA, Ucar R, Karahan AY. Familial mediterranean fever. Acta Medica (Hradec Kralove). 2014;57(3):97-104.

[2] Lidar M, Zandman-Goddard G, Shinar Y, Zaks N, Livneh A, Langevitz P. SLE and FMF: A possible negative association between the two disease entities-report of four cases and review of the literature. Lupus. 2008;17(7):663-669.

[3] Erten S, Taskaldiran I, Yakut ZI. Are systemic lupus erythematosus patients carrying MEFV gene less prone to renal involvement? report of three cases and review of the literature. Ren Fail. 2013;35(7):1013-1016.

[4] Shinar Y, Kosach E, Langevitz P, et al. Familial mediterranean Fever gene (MEFV) mutations as a modifier of systemic lupus erythematosus. Lupus. 2012;21(9):993-998

Disclosure of Interests: : None declared

DOI: 10.1136/annrheumdis-2020-eular.2305

\section{AB0420 RISK OF DEVELOPING TYPE 2 DIABETES MELLITUS IN PATIENTS WITH SYSTEMIC LUPUS ERYTHEMATOSUS}

L. Kondrateva ${ }^{1}$, T. Popkova ${ }^{1}$, E. Nasonov ${ }^{1}$, A. Lila ${ }^{1} .{ }^{1}$ V.A.Nasonova Research Institute of Rheumatology, Moscow, Russian Federation

Background: Patients with systemic lupus erythematosus (SLE) have higher than in general population prevalence of diabetes mellitus (DM). Hyperinsulinemia is a predictor of developing type $2 \mathrm{DM}$, however routine measurement of insulin levels for DM risk assessment is uncomfortable in daily clinical practice. International Diabetes Federation recommends the use of patient questionnaires to quickly identify people who may be at a higher risk of DM development.

Objectives: To determine the 10-years risk of developing type 2 DM in SLE patients using dedicated questionnaire - Finnish Type 2 Diabetes Risk Assessment Form (FINDRISK) data.

Methods: The study included 92 SLE patients without DM (83 women, 9 men $39[34 ; 47]$ years old). The median disease duration was $6[2,14]$ years, SLEDAI-2K was 4[2;8]. SLE pts were treated with glucocorticoids (GC) $(89 \%)$ and hydroxychloroquine $(78 \%)$, immunosuppressive drugs $(28 \%)$ and biological agents (10\%). The control group consisted of 88 subjects without systemic rheumatic diseases, inflammatory arthritis or DM, matched by age and sex with SLE patients. Eight items of FINDRISK questionnaire (age, overweight, abdominal obesity, family history of diabetes, physical inactivity, eating habits, history of antihypertensive drugs treatment, history of hyperglycemia) were taken into account to calculate the total risk score (TS). The risk of developing DM within following 10 years is regarded as low (1\%) or slightly elevated (4\%) with TS $\leq 11$ points, as moderate $(17 \%)$, high $(33 \%)$ or very high $(50 \%)$ with TS $\geq 12$ points. Results: The risk of developing DM was low or slightly elevated in 65 (71\%) SLE pts and moderate, high or very high in $27(29 \%)$ pts. The difference was significant compared with the control group, in which $76(86 \%)$ subjects had a low or slightly elevated risk and $12(14 \%)$ had a moderate, high or very high risk $(p=0,01)$. The number of risk factors $(4[2 ; 5])$ and the median TS of SLE pts $(9[5 ; 12]$ points) were higher than values in control subjects $(3[2,4]$ factors and $6[3 ; 9]$ points, respectively) ( $p<0,01$ for both). DM risk factors profiles were similar in two groups, except for higher prevalence of abdominal obesity ( $66 \%$ vs $41 \%$ $p<0,01)$ and history of antihypertensive drugs treatment $(57 \%$ vs $17 \%, p<0,01)$ in SLE. There were positive correlations between TS and CRP levels $(r=0,25$ $p=0,02)$, SLICC $(r=0,36, p<0,01), H A Q(r=0,29, p<0,01)$, and negative correlations between TS and SLEDAI-2K $(r=-0,32, p<0,01)$, glomerular filtration rate by CKD-EPI $(r=-0,23, p=0,03)$. Current $G C$ use had no influence on TS values in SLE.

Conclusion: Patients with SLE were more likely than individuals without systemic rheumatic diseases to have a moderate, high and very high risk of developing DM, and therefore, required interventions to prevent the metabolic disease. Increased risk of developing DM was associated with most common traditional factors, especially by abdominal obesity and regular use of antihypertensive drugs that can be considered a kind of equivalent to the presence of hypertension. Curtain contribution of inflammation, lupus activity and irreversible damage index can't be ignored. Clarification of SLE-specific phenomena in DM pathogenesis requires further research.

Disclosure of Interests: : None declared

DOI: 10.1136/annrheumdis-2020-eular.4087

\section{AB0421 1 EFFECT OF BODY WEIGHT ON COMPLEMENT LEVELS IN SYSTEMIC LUPUS ERYTHEMATOSUS}

L. Kondrateva ${ }^{1}$, T. Popkova ${ }^{1}$, E. Nasonov ${ }^{1}$, A. Lila ${ }^{1} .{ }^{1}$ V.A.Nasonova Research Institute of Rheumatology, Moscow, Russian Federation

Background: The complement system is a recognized biomarker for diagnosis or monitoring of disease activity in systemic lupus erythematosus (SLE) patients (pts). But on the other hand, it has been linked to insulin resistance and obesity in general population.

Objectives: To find out whether overweight/obesity can modify C3 or C4 levels in SLE pts.

Methods: A total of 92 SLE pts (83 women, 9 men, 39 [34;47] years old) were enrolled in the study. Median disease duration was $6[2 ; 14]$ years, and SLE activity using SLEDAI-2K was $4[2 ; 8]$. SLE pts were treated with glucocorticoids $(89 \%)$, hydroxychloroquine (78\%), immunosuppressants $(28 \%)$, biologics $(10 \%)$ The overweight/obesity status was determined by World Health Organization criteria in patients with body mass index $(\mathrm{BMI}) \geq 25 \mathrm{~kg} / \mathrm{m} 2$.

Results: Overweight/obesity were established in $46 \%$ SLE pts. Overweight obese SLE pts were older than pts with normal BMI $(40[36 ; 48]$ vs $37[31 ; 44]$ years, $p=0,02)$, and had lower SLEDAI-2K $(3[2 ; 6]$ vs $6[4 ; 8], p<0,01)$. Lower C3 concentrations were found in $36 \%$ overweight/obese pts vs $68 \%$ pts with normal weight $(p<0,01)$, decreased C4 levels - in $19 \%$ vs $30 \%$ pts $(p=0,33)$, median C3 concentrations were $0,98[0,81 ; 1,14] \mathrm{g} / \mathrm{l}$ vs $0,84[0,69 ; 0 ; 96] \mathrm{g} / \mathrm{l}(\mathrm{p}<0,01)$, and C4 levels were $0,15[0,10 ; 0,19] \mathrm{g} / \mathrm{l}$ vs $0,12[0,09 ; 0,16] \mathrm{g} / \mathrm{l}$, respectively $(p=0,03)$. C3 and C4 levels negatively correlated with SLEDAI-2K ( $r=-0,5, p<0,01$ for both) the effect was more strongly pronounced in patients with $B M l \geq 25 \mathrm{~kg} / \mathrm{m} 2(r=-0,6$ $p<0,01$ for both) than in those with normal weight $(r=-0,2, p=0,09$ for $C 3, r=-0,3$ $\mathrm{p}=0,04$ for $\mathrm{C} 4$ ).

Conclusion: Overweight/obesity status in SLE pts was associated with increased levels of complement proteins, therefore decreased C3 or C4 levels in patients with $\mathrm{BMI} \geq 25 \mathrm{~kg} / \mathrm{m} 2$ are more likely related to disease activity and, can potentially induce SLE flares.

Disclosure of Interests: : None declared

DOI: 10.1136/annrheumdis-2020-eular.4097

\section{$\mathrm{AB} 0422$ \\ LEFT VENTRICULAR ABNORMALITIES IN SYSTEMIC LUPUS ERYTHEMATOSUS PATIENTS FOLLOWED BY SEQUENTIAL ECHOCARDIOGRAPHY}

T. Kuga ${ }^{1}$, M. Matsushita ${ }^{1}$, K. Tada ${ }^{1}$, K. Yamaji ${ }^{1}$, N. Tamura ${ }^{1} .{ }^{1}$ Juntendo University School of Medicine, Department of Internal Medicine and Rheumatology, Tokyo, Japan

Background: Cardiovascular disease (CVD) is detected in up to $50 \%$ of systemic lupus erythematosus (SLE) patients ${ }^{1}$ and major cause of death ${ }^{2}$. Even clinically silent SLE patients can develop left ventricular (LV) diastolic dysfunction ${ }^{3}$ Proper echocardiographic follow up of SLE patients is required.

Objectives: To clarify how the prevalence of LV abnormalities changes over follow-up period and identify the associated clinical factors, useful in suspecting LV abnormalities.

Methods: 29 SLE patients ( 24 females and 5 men, mean age $52.8 \pm 16.3$ years, mean disease duration $17.6 \pm 14.5$ years) were enrolled. All of them underwent echocardiography as the baseline examination and reexamined over more than a year of follow-up period(mean $1075 \pm 480$ days) from Jan 